\title{
Mitochondrial DNA variation and cryptic speciation within the free-living marine nematode Pellioditis marina
}

\author{
S. Derycke ${ }^{1,4, *}$, T. Remerie ${ }^{1,4}$, A. Vierstraete ${ }^{2,4}$, T. Backeljau ${ }^{3}$, \\ J. Vanfleteren ${ }^{2,4}$, M. Vincx ${ }^{1}$, T. Moens ${ }^{1}$ \\ ${ }^{1}$ Department of Biology, Marine Biology Section, Ghent University, Krijgslaan 281, S8, 9000 Ghent, Belgium \\ ${ }^{2}$ Department of Biology, Ghent University, K. L. Ledeganckstraat 35, 9000 Ghent, Belgium \\ ${ }^{3}$ Royal Belgian Institute of Natural Sciences, Vautierstraat 29, 1000 Brussels, Belgium \\ ${ }^{4}$ CeMoFE, Ghent University, K. L. Ledeganckstraat 35, 9000 Ghent, Belgium
}

\begin{abstract}
An inverse correlation between dispersal ability and genetic differentiation among populations of a species is frequently observed in the marine environment. We investigated the population genetic structure of the free-living marine nematode Pellioditis marina. A total of $426 \mathrm{bp}$ of the mitochondrial cytochrome oxidase subunit 1 (COI) gene were surveyed on a geographical scale of approximately $100 \mathrm{~km}$ during spring 2003. Nematodes were collected from 2 coastal locations in Belgium, and from 2 estuaries and a saltwater lake (Lake Grevelingen) in The Netherlands. Molecular variation was assessed with the single-strand conformation polymorphism (SSCP) method. In total, 32 different haplotypes were observed, and sequence divergence among 452 individuals ranged from 0.2 to $10.6 \%$. We discovered 4 distinct mitochondrial lineages, with low divergences within the lineages ( 0.2 to $1.6 \%)$ and high divergences between the lineages (5.1 to $10.6 \%)$. The nuclear ribosomal ITS (internal transcribed spacer) region showed concordant phylogenetic patterns, suggesting that nematode species diversity may be considerably underestimated. Analysis of molecular variance (AMOVA) indicated a strong genetic differentiation among populations. The Lake Grevelingen population was clearly differentiated from all other populations, but genetic structuring was also significant within the Westerschelde and was correlated with gradients in salinity and pollution. The observed population genetic structure is in accordance with the limited active dispersal capacity of $P$. marina, but is at variance with its significant potential for passive dispersal. We therefore suggest that autecological characteristics, including short generation time, high colonization potential and local adaptation, may be at the basis of this nematode's population genetic structure.
\end{abstract}

KEY WORDS: Pellioditis marina · Single-strand conformation polymorphism • Cryptic species · Population genetic structure

\section{INTRODUCTION}

Many marine populations are thought to be demographically open because of long-distance larval dispersal (Caley et al. 1996). During the last decade, however, unexpectedly high levels of genetic differentiation have been reported for marine organisms with supposedly high dispersal capabilities (e.g. Taylor \&
Hellberg 2003, Caudill \& Bucklin 2004, Ovenden et al. 2004), illustrating that straightforward predictions on the relationship between dispersal ability and genetic differentiation remain problematic. Fewer studies have focused on species with low(er) dispersal abilities (Schizas et al. 1999, 2002, Kirkendale \& Meyer 2004), where population genetic structuring is expected to be higher (Avise et al. 1987, Palumbi 1994). Factors 
influencing gene flow in marine species are roughly divided into physical (e.g. ocean currents, habitat characteristics) and biological (e.g. spawning season, predation, larval and adult behavior) categories (Hohenlohe 2004). These characteristics limit the dispersal abilities of planktonic larvae, and render marine environments less open than previously thought. Furthermore, the issue of spatial scale may further complicate the discussion about open versus closed marine populations (Cowen et al. 2000, Camus \& Lima 2002).

In addition, population genetic surveys have also revealed that many marine 'species' are in fact species complexes involving morphologically cryptic taxa (Knowlton 1993, Todaro et al. 1996, Bond \& Sierwald 2002, Mathews et al. 2002, McGovern \& Hellberg 2003). Such complexes are especially prominent in small invertebrates with few taxonomically diagnostic characters (Rocha-Olivares et al. 2001). This taxonomic confusion evidently complicates the interpretation of distribution and dispersal patterns in the marine environment (Kirkendale \& Meyer 2004).

In this study, we investigate the population genetic structure of the free-living marine nematode Pellioditis marina Andrassy, 1983 (syn. Rhabditis marina Bastian, 1865) over a fairly small geographic area. Nematodes are the most abundant metazoans on earth, and they are highly speciose at very small $\left(<\mathrm{m}^{2}\right)$ to global scales, with estimates of total species numbers (including zooand phytoparasitic species) ranging from $10^{5}$ (Coomans 2000) to $10^{8}$ (Lambshead 1993). Their omnipresence and high diversity combined with functional variability render them an interesting model group to test concepts about the link between structural and functional biodiversity (Coomans 2002, De Mesel et al. 2003).

Most marine nematodes are endobenthic organisms with very limited active dispersal capacities. Passive (through erosion) and active (Wetzel et al. 2002) emergence into the water column does, however, occur, and passive dispersal through water currents, waterfowl or ballast water is plausible but hitherto poorly studied. Pellioditis marina typically frequents standing and decomposing macroalgae in the littoral zone of coastal environments (Moens \& Vincx 2000b) and may therefore be more prone to passive resuspension and transport (e.g. through 'rafting') than typically endobenthic nematodes. Its high reproductive capacity (up to 600 eggs female ${ }^{-1}$ under optimal conditions; Vranken \& Heip 1983) and short generation time ( $<3 \mathrm{~d}$ under optimal conditions; Vranken \& Heip 1983, Moens \& Vincx 2000a) render this species a strong colonizer capable of establishing viable populations from 1 or a few gravid females. In view of these features, we expected some capacity for passive dispersal and gene flow, at least over limited geographical distances.
Several marine nematode species have wide to nearly cosmopolitan distributions. This also holds for Pellioditis marina, which has been reported from coastal environments in Europe, along the Mediterranean Sea, on both sides of the Atlantic Ocean (Inglis \& Coles 1961), Vancouver Island, Canada (Sudhaus \& Nirmrich 1989), New Zealand, North Africa, Australia, South America (Sudhaus 1974), and from both the Antarctic and Arctic archipelago (T. Moens unpubl.). Such a wide geographical distribution is at variance with the alleged limited dispersal capacities of nematodes. However, P. marina shows substantial morphological (Inglis \& Coles 1961, Sudhaus 1974), reproductive (oviparous versus ovoviviparous) and physiological variation. As an example, some populations thrive well at temperatures which are lethal to other populations (Moens \& Vincx 2000a). While this may partly reflect local adaptation and phenotypic plasticity, it may also relate to differentiation among cryptic taxa as a result of vicariance events. Hence, since marine nematode taxonomy heavily relies on morphological criteria, there is an urgent need for information on the population genetic structure and cryptic variation within such morphologically defined species in order to better understand their current distribution and dispersal patterns.

Against this background, we used 'single-strand conformation polymorphisms' (SSCP) (Orita et al. 1989, Sunnucks et al. 2000) and DNA sequencing to screen mitochondrial COI nucleotide sequence variation of Pellioditis marina on a small and largely continuous geographical scale (ca. $100 \mathrm{~km}$ ) along the Belgian coast and in the Scheldt Estuary (The Netherlands). This area comprises various suitable habitat types for Pellioditis marina, as well as several locations with different degrees of connectivity. This sampling design enabled us to test the influence of (1) different habitats (estuaries, lake and coast), (2) environmental gradients (salinity, pollution) and (3) geographic distance on the population genetic structure of a free-living nematode.

\section{MATERIALS AND METHODS}

Sample locations. Individuals of Pellioditis marina were collected from 10 locations in Belgium, The Netherlands and England during April to June 2003 (Fig. 1).

In Belgium, 2 coastal locations were sampled $(\mathrm{Ni}$, $\mathrm{Bl})$, representing true marine habitats with a coarse sandy sediment and direct impact of the sea. In The Netherlands, 7 localities were sampled: 6 in 2 arms of the Scheldt Estuary (5 in the Westerschelde: $\mathrm{Br}, \mathrm{Pa}_{\text {, }}$ $\mathrm{Ze}, \mathrm{Kr}, \mathrm{Sl}_{i} 1$ in the Oosterschelde: Os) and 1 in Lake 


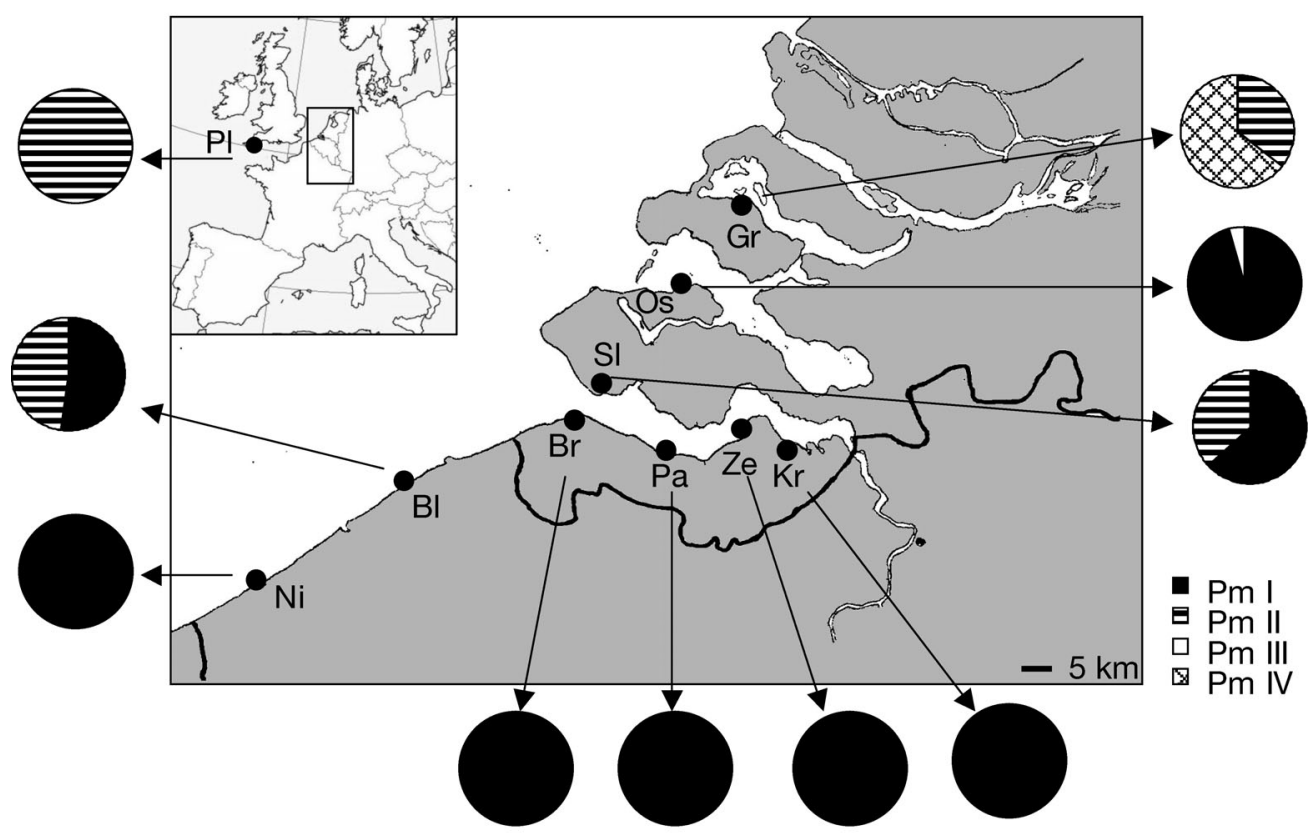

Fig. 1. Pellioditis marina. Locations of sampled populations and distribution of the 4 lineages (PmI, PmII, PmIII and PmIV).

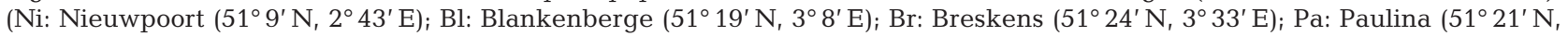
$\left.3^{\circ} 49^{\prime} \mathrm{E}\right)$; Ze: Zeedorp (51 $\left.24^{\prime} \mathrm{N}, 3^{\circ} 58^{\prime} \mathrm{E}\right)$; Kr: Kruispolderhaven $\left(51^{\circ} 22^{\prime} \mathrm{N}, 4^{\circ} 3^{\prime} \mathrm{E}\right)$; Sl: Sloehaven $\left(51^{\circ} 27^{\prime} \mathrm{N}, 3^{\circ} 36^{\prime} \mathrm{E}\right)$; Os: Oosterschelde estuary $\left(51^{\circ} 36^{\prime} \mathrm{N}, 3^{\circ} 50^{\prime} \mathrm{E}\right)$; Gr: Lake Grevelingen $\left(51^{\circ} 44^{\prime} \mathrm{N}, 3^{\circ} 57^{\prime} \mathrm{E}\right)$; Pl: Plymouth $\left(50^{\circ} 22^{\prime} \mathrm{N}, 4^{\circ} 9^{\prime} \mathrm{E}\right)$

Grevelingen (Gr). The Westerschelde is highly polluted, as it is a major drain for industrial and domestic wastes (De Wolf et al. 2004). Salinity varies between 12 and 35 in the upper part of the estuary comprising our sample locations. The Oosterschelde estuary is relatively clean and shows little to no variation in salinity (33 to 35). Lake Grevelingen also has a fairly constant salinity (32), but differs from the Oosterschelde by being cut off from the sea and by having no tidal currents. Both the Oosterschelde and Lake Grevelingen were transformed into their current basin-like shape by man during the 1960s to 1970s, and both environments are thus very young. Finally, in England 1 population was sampled in Plymouth, in the mouth of the River Plym (salinity of 32), in order to compare our small-scale patterns with larger-scale differentiation.

The following entities can thus be identified in our sampling design: (1) locations with no apparent physical barrier between them (2 Belgian coastal stations and 5 locations within the Westerschelde); (2) nearby locations recently isolated by both natural and manmade barriers ( 1 in Oosterschelde and 1 in Lake Grevelingen); (3) locations along a $40 \mathrm{~km}$ salinity and pollution gradient within the Westerschelde; (4) a more distant location in Plymouth (SW England), which is influenced by Atlantic currents.

Sample collection and processing. Approximately 50 individuals for each location were processed, except from Plymouth, for which only 31 individuals were analyzed. Fragments of Fucus sp. (Ulva sp. and Sargassum sp. in Lake Grevelingen) were randomly collected and incubated on agar slants (Moens \& Vincx 1998). Nematodes were subsequently allowed to colonize the agar for about $2 \mathrm{~d}$, which is less than 1 generation time under the incubation conditions used herein (Moens \& Vincx 2000a). Pellioditis marina was then identified under a dissecting scope using diagnostic morphological characters (Inglis \& Coles 1961) and handpicked from the agar with a fine needle. All individuals were transferred to sterile water and photographed digitally as a morphological reference. All worms were stored individually in 70 to $95 \%$ acetone until processed.

From stranded macroalgae in the Oosterschelde, we also isolated 2 individuals of the congener Pellioditis ehrenbaumi (syn. Rhabditis nidrosiensis [Sudhaus 1974], where Rhabditis and Pellioditis are subgenera of the genus Rhabditis [Sudhaus \& Fitch 2001]) and preserved these in acetone.

DNA extraction and PCR amplification. Prior to DNA extraction, the nematodes were transferred to sterile distilled water for approximately $30 \mathrm{~min}$ to remove traces of acetone. Individual nematodes were then transferred to $20 \mu \mathrm{l}$ lysis buffer $(50 \mathrm{mM} \mathrm{KCl}, 10 \mathrm{mM}$ Tris $\mathrm{pH}$ 8.3, $2.5 \mathrm{mM} \mathrm{MgCl}_{2}, 0.45 \% \mathrm{NP} 40,0.45 \%$ Tween20), cut into pieces with a razor and frozen for $10 \mathrm{~min}$ at $-20^{\circ} \mathrm{C}$. Proteinase K $\left(60 \mu \mathrm{g} \mathrm{ml}^{-1}\right)$ was added and sam- 
ples were incubated for $1 \mathrm{~h}$ at $65^{\circ} \mathrm{C}$, followed by $10 \mathrm{~min}$ at $95^{\circ} \mathrm{C}$. Finally, the DNA samples were centrifuged for $1 \mathrm{~min}$ at maximum speed (13200 rpm), and $1 \mu \mathrm{l}$ of extracted DNA was used as template for polymerase chain reactions (PCR).

A portion of the mitochondrial cytochrome oxidase $\mathrm{c}$ subunit 1 (COI) gene was amplified with Primers JB3 (5'-TTTTTTGGGCATCCTGAGGTTTAT-3') and JB4.5 (5'-TAAAGAAAGAACATAATGAAAATG-3') (Hu et al. 2002). Standard PCR amplifications were conducted in $25 \mu \mathrm{l}$ volumes for 35 cycles, each consisting of a $30 \mathrm{~s}$ denaturation at $94^{\circ} \mathrm{C}, 30 \mathrm{~s}$ annealing at $54^{\circ} \mathrm{C}$, and $30 \mathrm{~s}$ extension at $72^{\circ} \mathrm{C}$, with an initial denaturation step of $5 \mathrm{~min}$ at $94^{\circ} \mathrm{C}$ and a final extension step of $5 \mathrm{~min}$ at $72^{\circ} \mathrm{C}$. Because DNA amplification of nematodes from Lake Grevelingen consistently failed with these primers, we constructed a new reverse primer (JB5; 5'-AGCACCTAAACTTAAAACATAATGAAAATG-3') based on rhabditid nematode sequences from GenBank. We loaded $5 \mu \mathrm{l}$ of each PCR product onto a $1 \%$ agarose gel to check the size of the amplified product.

We additionally analyzed the nuclear ribosomal internal transcribed spacer region (ITS) of several mitochondrial haplotypes. The primers from Vrain et al. (1992) were modified: VRAIN 2F (5'-CTTTGTACACACCGCCCGTCGCT-3') and VRAIN 2R (5'-TTTCACTCGCCGTTACTAAGGGAATC-3'); these primers anneal in the conserved $28 \mathrm{~S}$ and $18 \mathrm{~S}$ region of the ribosomal DNA and amplify a product of approximately $900 \mathrm{bp}$ (ITS-1, 5.8S and ITS-2). PCR conditions were similar to those for amplification of the COI fragment, except for the final extension step, which lasted $10 \mathrm{~min}$ instead of 5 .

Single-strand conformation polymorphism (SSCP). For SSCP analysis, $2.5 \mu \mathrm{l}$ of PCR product was mixed with $5.5 \mu \mathrm{l}$ of loading dye (5\% EDTA, 95\% formamide, $0.05 \%$ bromophenol blue), denaturated for $5 \mathrm{~min}$ at $95^{\circ} \mathrm{C}$, and put immediately on ice until loading on a non-denaturating polyacrylamide gel $(0.5 \mathrm{~mm}$ thick, $2 \%$ crosslinking and $5 \%$ glycerol). For these horizontal gels, electrode strips were made with Tris/Hac $(0.45 \mathrm{M})$ and Tris/Tricine $(0.8 \mathrm{M})$ buffers. The conditions for electrophoresis $\left(15 \mathrm{~W}, 4 \mathrm{~h}\right.$ at $\left.5^{\circ} \mathrm{C}\right)$ were standardized for optimal resolution of bands, allowing the detection of single base differences for the $426 \mathrm{bp}$ COI fragment. Zhu \& Gasser (1998) showed that SSCP has the capacity to detect 75 to $95 \%$ of the point mutations using fragments of $200 \mathrm{bp}$ or less, although the same authors showed that sequence heterogeneity can also be displayed in fragments of 440 to $550 \mathrm{bp}$. A single point mutation in a $530 \mathrm{bp}$ fragment of the ITS-2 sequence of Toxocara cati was also detected by this method (Zhu et al. 1998). After electrophoresis, haplotypes were visualized with a DNA silver-staining kit
(Amersham Biosciences) and scored by their relative mobility.

DNA sequencing. All samples with different SSCP patterns were sequenced with both the forward and reverse primers as described earlier. To ensure that band mobilities were consistent with actual sequence variability, we additionally sequenced $10 \%$ of the samples from every location. Our SSCP conditions proved capable of distinguishing all haplotypes, except for 1 very rare haplotype $(\mathrm{n}=2$, in Sloehaven, $\mathrm{Sl}$ ) which was omitted from the data set. Ribosomal ITS fragments were not analyzed with SSCP but were sequenced directly.

Sequencing was performed using a Perkin Elmer ABI Prism 377 automated DNA sequencer. The PCR product was purified with shrimp alkaline phosphatase (1 $\mathrm{U} \mathrm{Hl}^{-1}$, Amersham E70092Y) and exonuclease I (20 $\mathrm{U} \mathrm{Hl}^{-1}$, Epicentre Technologies X40505K) and cycle-sequenced using the ABI Prism BigDye V 2.0 Terminator Cycle Sequencing kit.

Data analysis. Genetic diversity: Standard measures of genetic variation within populations, such as nucleotide diversity $(\pi)$ (Nei 1987) and gene diversity (h) (Tajima 1983, Nei 1987) were calculated using ARLEQUIN Version 2.0 (Schneider et al. 2000). Sequences were aligned with ClustalV 1.64b (Higgins et al. 1991) and were trimmed for further phylogenetic analysis in PAUP* 4.0 beta 10 (Swofford 1998). MODELTEST 3.06 (Posada \& Crandall 1998) was used to determine that the GTR $+\mathrm{I}+\mathrm{G}$ model was the most suitable for maximum likelihood analyses of our mitochondrial and nuclear data. The corresponding sequences of the closely related, marine/estuarine species Pellioditis ehrenbaumi were used for outgroup comparison (Accession Nos. AJ867056 for COI and AJ867073 for ITS). Maximum parsimony (MP) and neighbor-joining (NJ) trees were inferred with 1000 bootstrap replicates and 10000 rearrangements, while maximum likelihood (ML) trees were inferred from 100 bootstrap replicates and 500 rearrangements. Trees were obtained via stepwise addition, and a treebisection-reconnection branch swapping algorithm was used. Sequences were added randomly in 10 replicate trials, with 1 tree held at each step. To explore the intraspecific relationships between the observed haplotypes, a minimum spanning network was constructed with ARLEQUIN Version 2.0 and drawn by hand in Microsoft PowerPoint. Ambiguities in the network were resolved following the criteria suggested by Crandall \& Templeton (1993).

Population genetic structure: The genetic structure of Pellioditis marina was analyzed with ARLEQUIN's AMOVA (analysis of molecular variance). This procedure calculates the molecular variance and $\Phi$-statistics among and within populations, and the significance 
of the variance components is tested by permuting haplotypes among populations (Excoffier et al. 1992). AMOVA was performed for all sequences combined and, where possible, for every clade separately.

Genetic distances (which are a measure of the variability within versus between populations) between different populations were also calculated with ARLEQUIN, using the Tamura and Nei correction for different transversion and transition rates. This model also distinguishes between different transition rates among purines and pyrimidines (Tamura \& Nei 1993). Table-wide significance levels of the p-values obtained with 10000 permutations were corrected for multiple tests according to the sequential Bonferroni method (Rice 1989). To visualize the genetic distances between the different populations, a multidimensional scaling (MDS) plot was drawn using the program Primer 5.2.9 (Clarke \& Gorley 2001).

To test the isolation-by-distance model (IBD; Slatkin 1993), geographic and genetic distances were compared using a Mantel test as implemented in ARLEQUIN. The geographic distance between populations was measured as the shortest continuous water-surface distance. The number of permutations was set at 1000 . The strength of the IBD relationship was determined with reduced major axis (RMA) regression as implemented in the program IBD 1.5 (Bohonak 2002).

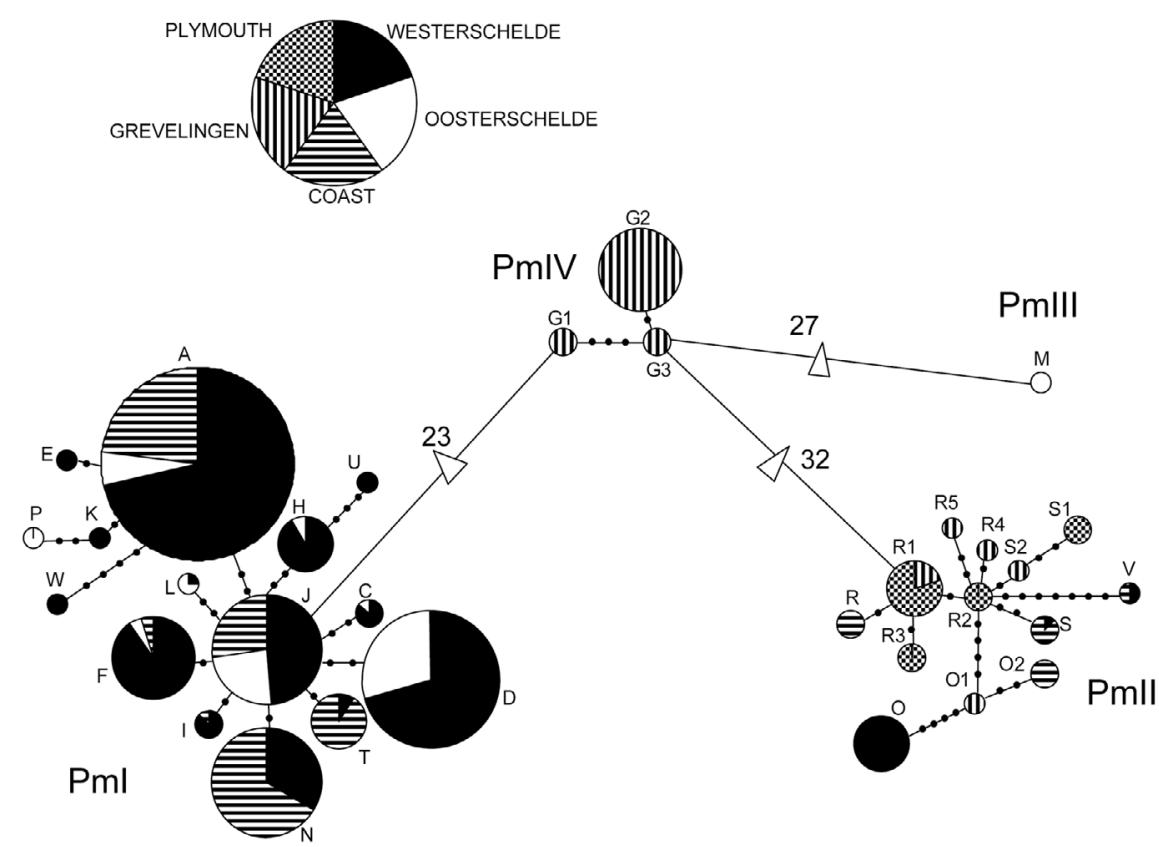

Fig. 2. Pellioditis marina. Minimum spanning network of mtDNA COI sequences. Sizes of circles are proportional to frequency of the 32 haplotypes (see Table 1) in total sample. Shared haplotypes among different hydrodynamic regions are represented by frequency diagrams. $(\bullet)$ Substitutions; $(\Delta) 23$ to 32 substitutions

Table 1. Pellioditis marina. Distribution of the 32 haplotypes among sampling locations. Haplotype diversity (h) and nucleotide diversity $(\pi)$ for each location are also indicated; $n$ : number of individuals analyzed. Sample location abbreviations as in Fig. 1

\begin{tabular}{|c|c|c|c|c|c|c|c|c|c|c|c|c|c|c|c|c|c|c|c|c|c|c|c|c|c|c|c|c|c|c|c|c|c|c|c|}
\hline & A & C & $\mathrm{D}$ & $\mathrm{E}$ & $\mathrm{F}$ & $\mathrm{H}$ & I & $\mathrm{J}$ & K & $\mathrm{L}$ & M & $\mathrm{N}$ & $\mathrm{O}$ & $\mathrm{P}$ & $\mathrm{R}$ & $\mathrm{S}$ & $\mathrm{T}$ & $\mathrm{U}$ & V & W & G1 & G2 & G3 & $\mathrm{R} 1$ & $\mathrm{R} 2$ & $\mathrm{R} 3$ & $\mathrm{R} 4$ & R5 & O1 & $\mathrm{O} 2$ & S1 & $\mathrm{S} 2$ & $\mathrm{n}$ & $h$ & $\pi$ \\
\hline $\mathrm{Br}$ & 17 & - & 16 & - & 8 & 5 & - & 1 & - & - & - & 2 & - & - & - & - & - & - & - & - & - & - & - & - & - & - & - & - & - & - & - & - & 49 & 0.7491 & 0.0072 \\
\hline $\mathrm{Pa}$ & 15 & - & 13 & 3 & 1 & 2 & 3 & 1 & - & - & - & 8 & - & - & - & - & - & 3 & - & - & - & - & - & - & - & - & - & - & - & - & - & - & 49 & 0.8121 & 0.0086 \\
\hline $\mathrm{Ze}$ & 16 & 4 & 17 & - & 1 & 3 & 4 & 2 & 2 & - & - & - & - & - & - & - & - & - & - & - & - & - & - & - & - & - & - & - & - & - & - & - & 49 & 0.7679 & 0.0075 \\
\hline $\mathrm{Kr}$ & 33 & - & 1 & - & 9 & - & - & - & - & - & - & 1 & - & - & - & - & - & - & - & - & - & - & - & - & - & - & - & - & - & - & - & - & 44 & 0.4038 & 0.0034 \\
\hline $\mathrm{Sl}$ & 6 & 2 & 5 & - & - & 1 & - & 12 & - & 1 & - & - & 15 & - & - & 1 & 1 & - & 1 & 1 & - & - & - & - & - & - & - & - & - & - & - & - & 46 & 0.8097 & 0.1807 \\
\hline Os & 7 & 1 & 22 & - & 1 & 1 & - & 8 & - & 3 & 2 & - & - & 2 & - & - & - & - & - & - & - & - & - & - & - & - & - & - & - & - & - & - & 47 & 0.7364 & 0.0237 \\
\hline $\mathrm{Bl}$ & 22 & - & - & - & - & - & 1 & - & - & - & - & - & - & - & 6 & 7 & - & - & 1 & - & - & - & - & - & - & - & - & - & - & 7 & - & - & 44 & 0.6956 & 0.1995 \\
\hline $\mathrm{Ni}$ & 6 & - & - & - & 1 & - & - & 9 & - & - & - & 22 & - & - & - & - & 10 & - & - & - & - & - & - & - & - & - & - & - & - & - & - & - & 48 & 0.7101 & 0.0038 \\
\hline Gr & - & - & - & - & - & - & - & - & - & - & - & - & - & - & - & - & - & - & - & - & 7 & 20 & 2 & 3 & - & - & 3 & 4 & 2 & - & - & 4 & 45 & 0.7667 & 0.1689 \\
\hline $\mathrm{Pl}$ & - & - & - & - & - & - & - & - & - & - & - & - & - & - & - & - & - & - & - & - & - & - & - & 12 & 8 & 6 & - & - & - & - & 5 & - & 31 & 0.7441 & 0.0045 \\
\hline Total & 122 & 7 & 74 & 3 & 21 & 12 & 8 & 33 & 2 & 4 & 2 & 33 & 15 & 2 & 6 & 8 & 11 & 3 & 2 & 1 & 7 & 20 & 2 & 15 & 8 & 6 & 3 & 4 & 2 & 7 & 5 & 4 & 452 & & \\
\hline
\end{tabular}



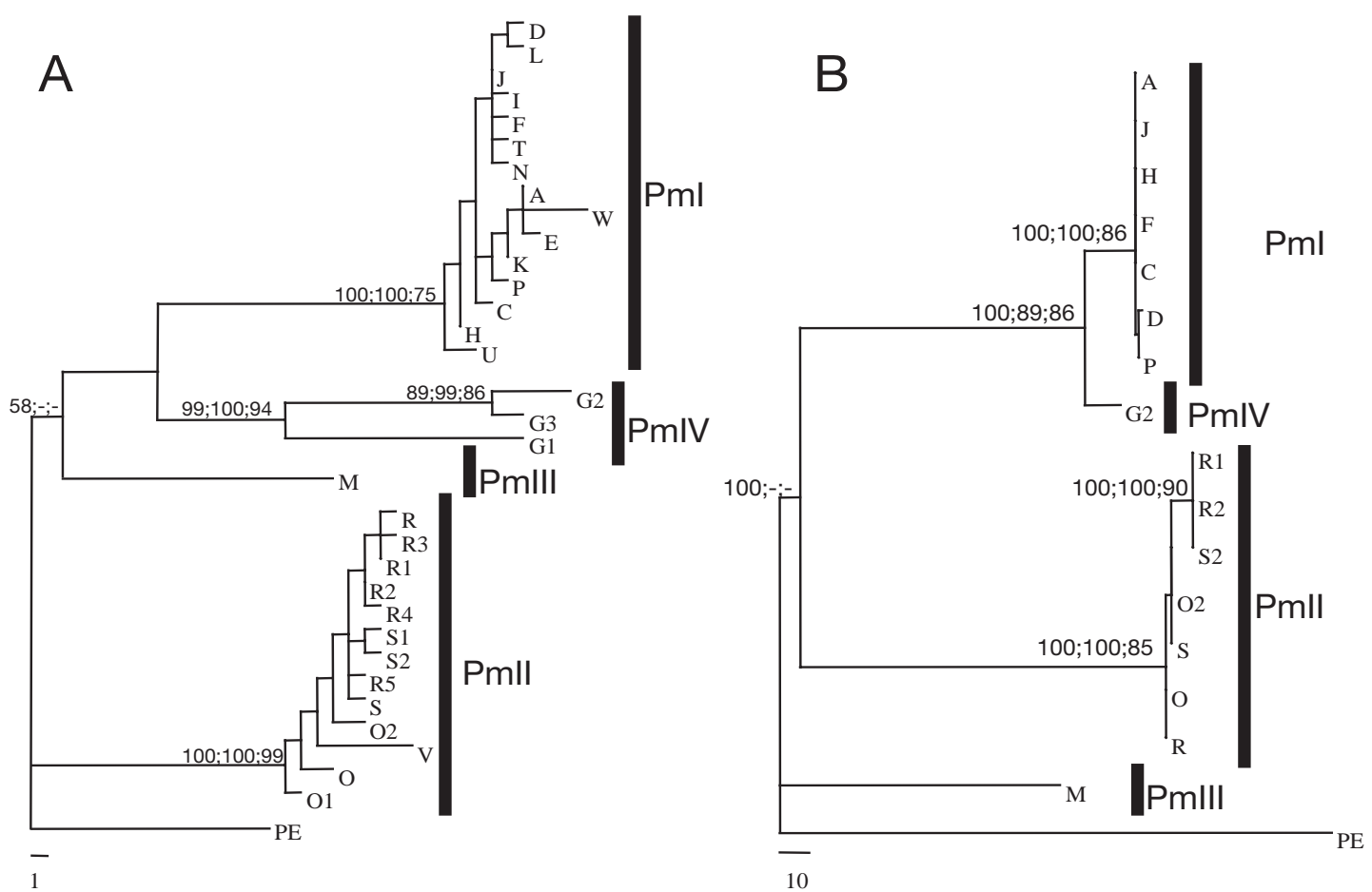

Fig. 3. Pellioditis marina. Maximum parsimony trees for (A) COI and (B) ribosomal ITS sequences. The 3 sets of bootstrap values on branches represent (from left to right) maximum parsimony, neighbor-joining and maximum likelihood, respectively. PmI, II, III and IV: 4 clades; congener P. ehrenbaumi (PE) was used as outgroup species

(Appendix 1; see www.int-res.com/articles/suppl/ derycke_appendix.pdf), 51 of which were parsimony informative, involving 44 synonymous substitutions and 7 replacement sites. Pairwise divergences between the COI sequences ranged from $0.23 \%$ (1 base substitution) to $9.6 \%$ (41 substitutions), most of them being third-base transversions. All sequences are available in GenBank under Accession Nos. AJ867447 to AJ867478.

The minimum spanning network revealed 32 haplotypes (Fig. 2). For convenience, all 5 locations within the Westerschelde were grouped ('Westerschelde') and the 2 Belgian coastal locations were pooled ('coast'). The haplotypes are clearly divided into 4 distinct groups (PmI, PmII, PmIII and PmIV), with low numbers of substitutions within each group (1 to 7 ), and high numbers between groups (23 to 32). PmI and PmII consist of 15 and 13 haplotypes, respectively, and are clearly more diverse than the PmIII (only 1 haplotype) and PmIV (only 3 haplotypes) groups. Haplotype relations within Groups PmI and PmII display a starlike pattern, with the rarer haplotypes showing a higher amount of mutational differences. Furthermore, the haplotypes within Group PmI have much higher frequencies than haplotypes from the other groups, Haplotypes A, D, J and N being particularly abundant in the Westerschelde and on the Belgian coast. More- over, the commonest haplotypes, A and D, are present at all locations, except Blankenberge, Plymouth and Lake Grevelingen. Haplotypes belonging to Group PmIV are restricted to Lake Grevelingen, G2 being the most abundant. PmII haplotypes are rare in the Wester- and Oosterschelde, but comprise all individuals from Plymouth. Haplotypes R1 and O have the highest frequency in this group; 4 haplotypes are unique to Lake Grevelingen (O1, R4, R5 and S2) and 3 are unique to Plymouth (R2, R3 and S1). Group PmIII consisted of a single haplotype at very low frequency (Haplotype $M, n=2$ ). This haplotype was only found in the Oosterschelde.

Within the PmI group, 2 replacement sites were observed (represented by the rarely encountered Haplotypes $\mathrm{U}[\mathrm{n}=3]$ and $\mathrm{W}[\mathrm{n}=1]$ ). Within the PmII group, 6 replacement sites were detected, 3 of which were observed in the rare haplotype $\mathrm{V}(\mathrm{n}=2)$.

\section{Phylogenetic analyses}

\section{Mitochondrial COI gene}

A heuristic search identified the 20 most parsimonious trees, which differed from each other only in the position of haplotype $\mathrm{V}$ within its clade; 1 of the MP 
trees is shown in Fig. 3A. Maximum likelihood and neighbor-joining methods gave generally consistent trees. Support for the monophyly of the 3 major clades (PmI, PmII, PmIV) is strong (>95\%), while the node that unites haplotype $\mathrm{M}$ with those of Clades PmI and PmIV lacks good support and was absent in the ML and NJ analyses.

\section{Nuclear rDNA}

Because the COI fragment showed high divergences between and low divergences within clades, we analyzed a fragment of the nuclear spacer region. The nuclear genome evolves independently from the mitochondrial genome, and is subject to different evolutionary forces. A concordant pattern between these 2 markers will therefore provide extra support to the observed mitochondrial subdivision in 4 clades.

In total, 827 to $859 \mathrm{bp}$ of the ribosomal ITS region were sequenced from 17 individuals (Accession Nos. AJ867057 to AJ867072), representing the most abundant mitochondrial haplotypes of each mitochondrial clade. Because the PmIII clade consisted of only 1 haplotype, both individuals belonging to this clade were processed for the nuclear marker. The alignment (888 sites) of the 17 ITS sequences showed that 240 sites were variable $(27 \%), 233$ of these being parsimony informative. The heuristic search yielded a total of 91 most parsimonious trees, which differed only in the relative positions of individuals within clades (Fig. 3B). MP, NJ and ML analyses all separated the individuals into 3 major clades, supported by strong bootstrap values, and individuals of PmIII were separated from the other 3 groups showing a basal position in the phylogenetic tree. The length of the amplified region varied because of insertion/deletion differences between the 4 groups (Appendices 2 \& 3; see www.int-res.com/articles/suppl/ derycke_appendix.pdf). Within the PmII clade, a clustering of Sequences R1, R2 and S2 was supported by high bootstrap values and differed in 4 transitions and 3 transversions from the other PmII sequences. Within Clade PmI, all sequences were identical, except for Sequences

Table 2. Pellioditis marina. Divergence range (\%) between the 4 clades. Above diagonal: mtDNA COI fragment; below diagonal: nuclear ITS region

\begin{tabular}{|c|c|c|c|c|}
\hline & PmI & PmII & PmIII & PmIV \\
\hline PmI & & 8.1 to 10.6 & 7.0 to 7.8 & 5.8 to 7.5 \\
\hline PmII & 11.0 to 12.0 & & 8.5 to 10.1 & 8.0 to 9.8 \\
\hline PmIII & 20.9 to 21.1 & 20.3 to 21.1 & & 6.8 to 7.3 \\
\hline PmIV & 3.3 to 3.5 & 10.5 to 11.6 & 20.0 & \\
\hline
\end{tabular}

Table 3. Pellioditis marina. Number of fixed differences between the 4 clades. Above diagonal: mtDNA COI fragment; below diagonal: nuclear ITS region

\begin{tabular}{|lrrrr|}
\hline & PmI & PmII & PmIII & PmIV \\
\hline PmI & & 29 & 26 & 22 \\
PmII & 98 & 182 & 30 & 27 \\
PmIII & 186 & 178 & 25 \\
PmIV & 37 & 96 & 178 \\
\hline
\end{tabular}

$\mathrm{P}$ and $\mathrm{D}$, which differed in 1 and 2 transitions, respectively, from the other sequences.

Divergences within the clades ranged from 0 to $0.24 \%$ for Clade PmI, and from 0 to $0.81 \%$ for Clade PmII. Divergences among the different clades were much higher and are summarized in Table 2.

When the MP tree was calculated using gaps as a fifth base, no differences in topology were found, except for a better separation of the 2 groups within the PmII clade.

\section{Interspecific variation and geographical distribution}

The observation that both mitochondrial and nuclear markers show the same subdivision of the sampled individuals, raises the question as to whether Pellioditis marina may comprise several cryptic species. Table 3 shows the fixed differences, i.e. the number of base positions at which all sequences of one 'species' differ from all sequences of a second 'species' (Hey 1991), for both molecular markers between the different clades. PmIII has the highest number of fixed differences in the nuclear ITS marker, while PmII has the highest number of fixed differences in COI. The amount of unique fixed differences, i.e. the number of positions at which a species is different from all others (Kliman \& Hey 1993), shows the same pattern: PmIII has 155 unique fixed base differences and 5 unique fixed length differences, which are the highest numbers for the nuclear marker; PmII has 54 unique fixedbase differences and 4 unique length differences, while PmI and PmIV have 18 and 16 unique base differences and no unique length difference (Appendices $2 \& 3$ ). For COI, PmII has the highest amount of unique fixed differences (12), followed by PmIII (10), PmI (7) and PmIV (6) (Appendix 1).

Fig. 1 shows the geographical distribution of each clade along the sampled region. The PmI clade is clearly the most abundant and geographically widespread lineage. It is the dominant lineage within the Westerschelde and Oosterschelde, and is absent from Lake Grevelingen and Plymouth. In Plymouth, only the PmII clade was found and this clade is also abundant in 
Table 4. Pellioditis marina. Hierarchical analyses of variance across 10 populations. $\Phi$-statistics calculated for all data combined and for sequences allocated to their respective clades (PmI to IV). n: number of individuals analyzed; \%: percentage variance explained; $\mathrm{p}$ : significance level of $\Phi$-statistic

$$
\left({ }^{* * *}<0.0001\right)
$$

\begin{tabular}{|lcccc|}
\hline & $\mathrm{n}$ & $\%$ & $\Phi$ & $\mathrm{p}$ \\
\hline All sequences & 451 & & & \\
Among populations & & 55.90 & 0.56 & $* * *$ \\
Within populations & & 44.10 & & \\
PmI & 335 & & & \\
Among populations & & 18.76 & 0.19 & $* *$ \\
Within populations & & 81.24 & & \\
PmII & 85 & & & \\
Among populations & & 47.00 & 0.05 & $* *$ \\
Within populations & & 53.00 & & \\
PmIII & 2 & - & - & - \\
PmIV & 29 & - & - & - \\
\hline
\end{tabular}

Lake Grevelingen. PmIII is only encountered in the Oosterschelde and PmIV only in Lake Grevelingen. In several of our sample locations, 2 lineages occurred sympatrically.

\section{Population genetic structure}

A significant spatial population genetic structure is found when all sampling locations are pooled. This indicates that migration between the different locations is not sufficient to homogenize the COI gene pool. Of all molecular variation found, $55.9 \%\left(\Phi_{\mathrm{ST}}=0.559, \mathrm{p}<0.0001\right)$ is explained by differences among locations (Table 4). Omitting the Plymouth population, variation between locations is still significant $\left(\Phi_{\mathrm{ST}}=0.4471, \mathrm{p}<0.0001\right)$. The MDS plot of the genetic distances clearly shows a large divergence of the Plymouth and Lake Grevelingen samples: $60.14 \%$ of the variation $\left(\Phi_{\mathrm{CT}}=0.6014, \mathrm{p}<0.05\right)$ is caused by differences between Plymouth and Lake Grevelingen on the one hand, and the Belgian and Dutch populations on the other (Fig. 4A). The MDS plot does not change when Plymouth and Lake Grevelingen are omitted, although the percentage of variation explained by differences between the remaining popula- tions decreases to $30.58 \%\left(\Phi_{\mathrm{ST}}=0.30575, \mathrm{p}<0.0001\right)$. Examination of the distribution of the locations within the Westerschelde (Fig. 4B) reveals a clear distinction between the most upstream location (Kr) and 1 of the 2 most downstream locations ( $\mathrm{Sl})$. The highest genetic diversity is in Sloehaven $(h=0.81, \pi=0.181)$ and the lowest in Kruispolderhaven ( $h=0.404, \pi=0.003)$. No significant differentiation is apparent between the other locations (Breskens, Paulina and Zeedorp, $\Phi_{\mathrm{ST}}=$ $0.00315, p=0.3$ ) within this estuary. Genetic diversity at these locations is comparable but somewhat higher in Paulina (Table 1).

AMOVA was also performed on Clades PmI and PmII separately. The MDS plot in Fig. 4C shows the genetic distances of PmI between the sampled locations. The coastal zones (Bl and $\mathrm{Ni}$ ) are clearly differentiated from the Westerschelde and Oosterschelde populations, and AMOVA indicates a significant differentiation $(18.76 \%)$ among the locations $\left(\Phi_{\mathrm{ST}}=\right.$ $0.18762, \mathrm{p}<0.0001)$. Within the Westerschelde, PmI is still significantly structured, albeit this is less pronounced $\left(\Phi_{\mathrm{ST}}=0.08475, \mathrm{p}<0.0001\right)$. This mainly reflects differences between the most upstream location and the 3 other locations (Fig. 4C). The differentiation with the westernmost coastal location (Ni) is due to the presence of 1 haplotype unique to that location (Haplotype $\mathrm{T}$, except for 1 individual in $\mathrm{Sl}$ ). Haplotypes belonging to the PmII clade are also significantly structured, $47 \%$ of the total variation being explained by differences among locations $\left(\Phi_{\mathrm{ST}}=\right.$ 0.47003, $\mathrm{p}<0.0001$ ).

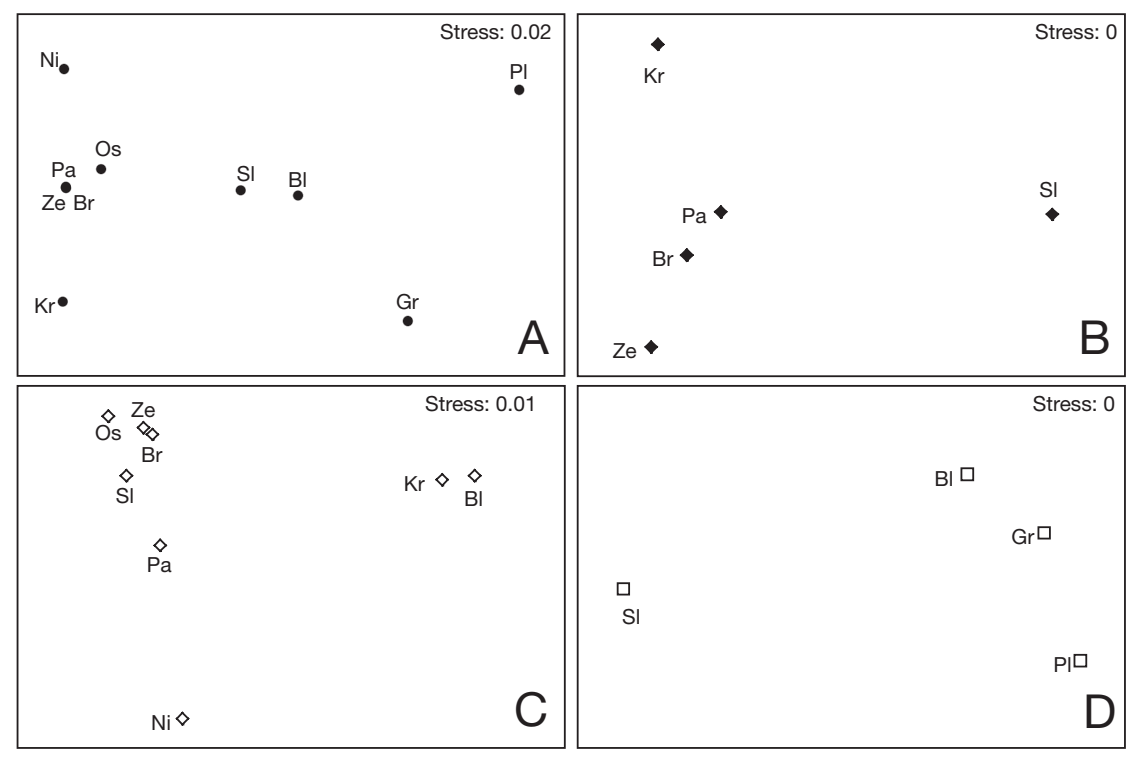

Fig. 4. Pellioditis marina. Multi-dimensional scaling (MDS) of Tamura \& Nei genetic distance matrix of COI fragment and associated stress value. (A) Complete data set (no distinction made between clades); (B) locations within Westerschelde (no distinction made between clades); (C) Clade PmI; (D) Clade PmII. Sample location abbreviations as in Fig. 1 


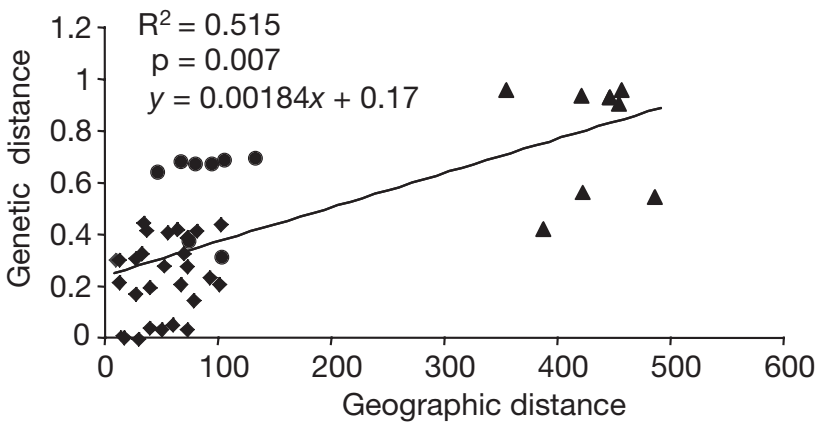

Fig. 5. Pellioditis marina. Scatter diagram of geographic distance versus genetic distance for population pairs com-

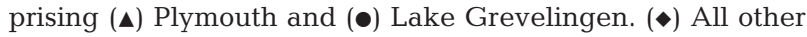
population pairs

\section{Isolation by distance}

Genetic and geographic distances are correlated when all sampled populations are included $(\mathrm{r}=0.7178$, $\mathrm{p}=0.007)$. More than $50 \%$ of the molecular variation is explained by geographic distance $\left(\mathrm{R}^{2}=0.515\right)$. Plotting both distances in a scatter diagram (Fig. 5) reveals a clear separation of nematodes from Plymouth and those from Lake Grevelingen. Calculating IBD between the populations from Belgium and The Netherlands (and thus omitting the Plymouth population) still gives a significant $(r=0.4725, p=0.037)$, albeit less strong, correlation.

\section{DISCUSSION}

\section{Population genetic structure}

Overall, there was a significant population genetic structuring over the sampled area. Even within the Westerschelde, locations were differentiated from each other. The strong differentiation of the Plymouth population ( $\mathrm{Pl}$, Fig. 4A) was caused by the presence of only PmII at this location. At first sight, these results support the idea of limited dispersal abilities in marine nematodes. Free-living nematodes are small, have an endobenthic life style and lack dispersive stages. Active dispersal is therefore restricted. However, Pellioditis marina typically lives on decomposing algae in littoral and coastal environments, and can passively disperse through rafting on floating algae (S. Derycke pers. obs.). The dominant currents in the North Sea transport macroalgae from SW England to the Belgian and Dutch coasts (Turrell 1992, Ducrotoy et al. 2000), and can therefore homogenize populations living on both sides of the North Sea. However, we found a strong differentiation between Plymouth and the Belgian coastal zone populations, as well as among those at the stations located in the small area sampled in Belgium and The Netherlands. One possible explanation is that passive dispersal may be inefficient. However, considering the high reproductive potential and short development times of $P$. marina (Vranken \& Heip 1983, Moens \& Vincx 2000a), even very small founder populations are expected to be sufficient for effective colonization. Therefore, the genetic structuring on our small geographical scale may rather be due to repeated colonization events combined with high reproductive rates (De Meester et al. 2002, Caudill \& Bucklin 2004). Monopolization of resources and local adaptation (which may be prominent in P. marina; Moens \& Vincx 2000a,b) can then produce persistent genetic structure over small spatial scales in the face of significant gene flow (De Meester et al. 2002).

The differentiation and lower genetic diversity ( $h=0.404, \pi=0.003$; Table 1$)$ of the most upstream location $(\mathrm{Kr})$ within the Westerschelde may well be linked to the lower salinity and/or higher pollution at this location, rather than by cessation of gene flow. It is in agreement with the range of Pellioditis marina in the Westerschelde, which extends only just beyond this most upstream sampling location (Moens \& Vincx 2000b). However, the salinity gradient in the Westerschelde is paralleled by a pollution gradient, rendering assignment of species ranges to either factor difficult. Moreover, a whole range of pollutants is present in this estuary, with unknown consequences for communities and species living there. Interestingly, De Wolf et al. (2004) also found a correlation of population genetic structure with the salinity/pollution gradient in the Westerschelde for the periwinkle Littorina littorea. Toxicants can influence the population genetic structure of a species by mutagenic, physiological or ecological effects, which can lead to a decrease in genetic variation and in frequency of haplotypes (De Wolf et al. 2004). Experimental studies with harpacticoid copepods indicate that severe bottlenecks can occur in populations exposed to toxicants (Street et al. 1998), and environmental history seems to have no effect on their survival ability when copepods are exposed to different concentrations of sediment-associated contaminants (Kovatch et al. 2000). In contrast, Schizas et al. (2001) observed differential survival of 3 harpacticoid copepod lineages and inferred that this differential survival might explain some of the genetic patterns observed in contaminated habitats.

Contrary to De Wolf et al. (2004), we found no clear differentiation between the Oosterschelde population and the downstream locations in the Westerschelde. Even though a storm-surge barrier between the Oosterschelde and the North Sea was constructed in 1986, this remains open most of the time. 
Exchange between neighboring populations is therefore still important.

The high degree of genetic differentiation of Lake Grevelingen is caused by the presence of the PmIV lineage, which is absent from all other locations.

\section{Cryptic speciation}

We found a high degree of intraspecific differentiation in the COI gene of Pellioditis marina.

Within the Nematoda, intraspecific variation has hitherto only been studied in parasitic species, with divergences of the COI gene ranging from 0.3 to $8.6 \%$ ( 0.3 to $8.4 \%$ in Oesophagostomum bifurcum: de Gruijter et al. 2002; 0.5 to $8.6 \%$ in Ancylostoma caninum, 0.3 to $3.3 \%$ in A. duodenale, 0.3 to $4.3 \%$ in Necator americanus: $\mathrm{Hu}$ et al. 2002). Interspecific divergences within genera range from 4.8 to $13.7 \%$ (11.5 to $13.7 \%$ within the genus Oesophagostomum, 4.8 to $11.1 \%$ within the genus Ancylostoma). These interspecific values are comparable with the divergences found between the 4 lineages in the COI gene of Pellioditis marina (5.8 to $10.6 \%$, Table 2). For comparison, divergences between $P$. marina and its congener $P$. ehrenbaumi range from 7.5 to $9.5 \%$. Nucleotide differences within lineages are much lower, and range from 0.25 to $1.7 \%$, lower than the within-species divergences described above. Furthermore, we found a large amount of fixed differences (= number of base positions at which all sequences of one lineage differ from all sequences of another lineage) in the COI fragment between our lineages (22 to 29; Table 3). Zhu et al. (2001) and Hu et al. (2002) found no fixed differences within sets of populations of A. duodenale and Contracaecum ogmorhini, and concluded that these populations belong to the same species. On the other hand, $\mathrm{Hu}$ et al. (2002) detected 4 unequivocal nucleotide positions in a $395 \mathrm{bp}$ region of the COI gene between individuals of $N$. americanus from China and Togo, suggesting that these individuals belong to distinct sets of genotypes as a consequence of geographical isolation over a long period of time.

The high levels of COI differentiation between the haplotype groups of Pellioditis marina are thus in the order of differences found between different species of parasitic nematodes and between congeneric species of Pellioditis. This observation, together with the high amount of fixed differences between these haplotype groups, suggest that the mitochondrial lineages represent different cryptic species of $P$. marina. When morphological stasis persists after speciation events, the resulting species may continue to diverge genetically in the absence of morphological differentiation (RochaOlivares et al. 2001). Especially in organisms with small body size, the number of taxonomically relevant characters decreases rapidly (Rocha-Olivares et al. 2001).

Analysis of the nuclear ribosomal spacer region is consistent with the hypothesis of cryptic speciation. This region is particularly useful for phylogenies among closely related taxa (taxa that have diverged within the last 50 million years) (Hillis \& Dixon 1991), and the region is generally of uniform length and composition within species (Hillis et al. 1991). Sequence differences within each lineage are low ( 0 to $0.81 \%)$. However, many fixed differences between the 4 lineages were found (Table 3). Lineages PmII and PmIII also contain 4 and 5 fixed-length differences, respectively (Appendices $2 \& 3$ ). The concordance between COI and the nuclear marker provides further support that Pellioditis marina consists of multiple cryptic species using the phylogenetic species and the genealogical concordance criteria (RochaOlivares et al. 2001). The existence of other cryptic species or intermediate lineages cannot be excluded, and additional sampling in time and on a larger geographical scale would probably uncover still more variation in $P$. marina.

We will perform hybridization experiments and detailed morphological analysis of the 4 Pellioditis marina lineages to further substantiate and describe these cryptic species. The ease with which P. marina can be cultured in laboratory conditions will also enable us to address differences in autecology.

\section{Distribution of the 4 lineages}

On the geographical scale sampled here, Clade $\mathrm{PmI}$ is the most abundant with an estuarine and coastal distribution (Fig. 1). Within PmI, Haplotypes $\mathrm{A}$ and $\mathrm{D}$ are very common within the Westerschelde, except in the most upstream location $(\mathrm{Kr})$, where only a single individual of Haplotype D was found. The 'star-like' pattern within PmI in the minimum spanning network suggests that Haplotype $\mathrm{J}$ is the oldest haplotype, which then gave rise to all other haplotypes of PmI.

Within the Westerschelde, a gradient of decreasing (organic and chemical) pollution occurs towards the sea, and at the same time salinity increases. Pellioditis marina is a marine and brackish water nematode, with an optimal fitness at salinities between 10 and 30 . However, these ranges are characteristic of populations rather than of species, and local adaptation as well as adaptation to culture conditions may be prominent (Moens \& Vincx 2000b). From these results, it seems likely that Haplotype A is the most tolerant of a range of salinities. In general, the PmI lineage seems to 
be more tolerant of fluctuating environmental conditions than the other haplotype groups. Lake Grevelingen has no tides, and in these stable conditions PmIV was the only haplotype group found. PmII was found in much lower frequency than the PmI species and contains many haplotypes which are unique to either Lake Grevelingen or to the Plymouth population. The most abundant haplotype $(\mathrm{R} 1=15)$ was shared between these 2 locations.

From Fig. 1, it is obvious that the 4 cryptic lineages occur sympatrically. As far as we know, Pellioditis marina is not a specialist feeder, nor is it constrained to a very strict abiotic environment (Moens \& Vincx $2000 a, b)$. Furthermore, we do not exclude that the cryptic lineages occur in a temporal succession, correlating with the decomposition stage of the algae, and hence the quality of the organic detritus on which they live. Whether speciation occurred sympatrically or allopatrically cannot be inferred from our data.

\section{CONCLUSIONS}

Although its active dispersal capacities are extremely limited, Pellioditis marina can disperse passively through rafting on floating algae. Our results suggest that this dispersal is either small or that pulsed colonization events occur. Therefore, information on life strategies, colonization potential and local adaptation is as important as knowledge of dispersal ability for interpreting the potential relationship between population genetic structure and dispersal capacity.

Phylogenetic analyses of the mitochondrial COI gene and the nuclear ITS region shows the existence of 4 cryptic lineages within the morphospecies Pellioditis marina. This cryptic speciation, found in only a small $(100 \mathrm{~km})$ geographical range of $P$. marina, has strong implications for diversity estimates within the $\mathrm{Ne}$ matoda, which are mainly based on morphological characteristics. Because P. marina has a very short generation time with a high reproductive output, extrapolations and generalizations to other nematode species have to be made carefully. Nevertheless, this result does indicate that the real species diversity within the phylum Nematoda is probably much higher than hitherto suggested.

Acknowledgements. S.D. acknowledges a grant from the Flemish Institute for the Promotion of Scientific-Technological Research (I. W. T.). T.M. is a postdoctoral fellow with the Flemish Fund for Scientific Research. Further financial support was obtained from Ghent University in BOF-projects 12050398 (GOA) and 011060002 . We gratefully acknowledge Dr. P. Somerfield (Plymouth Marine Laboratory) for his help in the collection of the Plymouth samples.

\section{LITERATURE CITED}

Avise JC, Arnold J, Ball RM, Bermingham E, Lamb T, Neigel JE, Reeb CA, Saunders NC (1987) Intraspecific phylogeography: the mitochondrial DNA bridge between population genetics and systematics. Annu Rev Ecol Syst 18: 489-522

Bohonak AJ (2002) IBD (isolation by distance): a program for analyses of isolation by distance. J Hered 93:153-154

Bond JE, Sierwald P (2002) Cryptic speciation in the Adenobolus excisus millipede species complex on the island of Jamaica. Evolution 56:1123-1135

Caley MJ, Carr MH, Hixon MA, Hughes TP, Jones GP, Menge BA (1996) Recruitment and the local dynamics of open marine populations. Annu Rev Ecol Syst 27: 477-500

Camus PA, Lima M (2002) Populations, metapopulations, and the open-closed dilemma: the conflict between operational and natural population concepts. Oikos 97 : 433-438

Caudill CC, Bucklin A (2004) Molecular phylogeography and evolutionary history of the estuarine copepod, Acartia tonsa, on the Northwest Atlantic coast. Hydrobiologia 511: 91-102

Clarke KR, Gorley RN (2001) Primer v5: user manual/tutorial. Primer-E, Plymouth

Coomans A (2000) Nematode systematics: past, present and future. Nematology 2:3-7

Coomans A (2002) Present status and future of nematode systematics. Nematology 4: 573-582

Cowen RK, Lwiza KMM, Sponaugle SU, Paris CB, Olson DB (2000) Connectivity of marine populations: open or closed? Science 287:857-859

Crandall KA, Templeton AR (1993) Empirical tests of some predictions from coalescent theory with applications to intraspecific phylogeny reconstruction. Genetics 134: 959-969

de Gruijter JM, Polderman Am, Zhu XQ, Gasser RB (2002) Screening for haplotypic variability within Oesophagostomum bifurcum (Nematoda) employing a single-strand conformation polymorphism approach. Mol Cell Probes 16:185-190

De Meester L, Gómez A, Okamura B, Schwenk K (2002) The monopolization hypothesis and the dispersalgene flow paradox in aquatic organisms. Acta Oecol 23: 121-135

De Mesel I, Derycke S, Swings J, Vincx M, Moens T (2003) Influence of bacterivorous nematodes on the decomposition of cordgrass. J Exp Mar Biol Ecol 296:227-242

De Wolf H, Blust R, Backeljau T (2004) The population genetic structure of Littorina littorea (Mollusca: Gastropoda) along a pollution gradient in the Scheldt estuary (The Netherlands) using RAPD analysis. Sci Total Environ 325:59-69

Ducrotoy JP, Elliott M, de Jonge VN (2000) The North Sea. Mar Pollut Bull 41:5-23

Excoffier L, Smouse P, Quattro J (1992) Analysis of molecular variance inferred from metric distances among DNA haplotypes: application to human mitochondrial DNA restriction data. Genetics 131:479-491

Hey J (1991) The structure of genealogies and the distribution of fixed differences between DNA sequence samples from natural populations. Genetics 128:831-840

Higgins DG, Bleasby AJ, Fuchs R (1991) Clustal V: improved software for multiple sequence alignment. CABIOS 8: 189-191

Hillis DM, Dixon MT (1991) Ribosomal DNA: molecular 
evolution and phylogenetic inference. Q Rev Biol 66: 411-437

Hillis DM, Moritz C, Porter CA, Baker RJ (1991) Evidence for biased gene conversion in concerted evolution of ribosomal DNA. Science 251:308-310

Hohenlohe PA (2004) Limits to gene flow in marine animals with planktonic larvae: models of Littorina species around Point Conception, California. Biol J Linn Soc 82:169-187

Hu M, Chilton NB, Zhu XQ, Gasser RB (2002) Single-strand conformation polymorphism-based analysis of mitochondrial cytochrome c oxidase subunit 1 reveals significant substructuring in hookworm populations. Electrophoresis 23:27-34

Inglis WG, Coles JW (1961) The species of Rhabditis (Nematoda) found in rotting seaweed on British beaches. Bull $\mathrm{Br}$ Mus (Nat Hist) Zool 7(6):320-333

Kirkendale LA, Meyer CP (2004) Phylogeography of the Patelloida profunda group (Gastropoda: Lottidae): diversification in a dispersal-driven marine system. Mol Ecol 13: $2749-2762$

Kliman RM, Hey J (1993) DNA sequence variation at the period locus within and among species of the Drosophila melanogaster complex. Genetics 133:375-387

Knowlton N (1993) Sibling species in the sea. Annu Rev Ecol Syst 24: 189-199

Kovatch CE, Schizas NV, Chandler T, Coull BC, Quattro JM (2000) Tolerance and genetic relatedness of three meiobenthic copepod populations exposed to sedimentassociated contaminant mixtures: role of environmental history. Environ Toxicol Chem 19:912-919

Lambshead PJD (1993) Recent developments in marine benthic biodiversity research. Oceanis 19:5-24

Mathews LM, Schubart CD, Neigel JE, Felder DL (2002) Genetic, ecological, and behavioral divergence between two sibling snapping shrimp species (Crustacea: Decapoda: Alpheus). Mol Ecol 11:1427-1437

McGovern TM, Hellberg ME (2003) Cryptic species, cryptic endosymbionts, and geographical variation in chemical defences in the bryozoan Bugula neritina. Mol Ecol 12: $1207-1215$

Moens T, Vincx M (1998) On the cultivation of free-living marine and estuarine nematodes. Helgol Meeresunters 52:115-139

Moens T, Vincx M (2000a) Temperature and salinity constraints on the life cycle of two brackish-water nematode species. J Exp Mar Biol Ecol 243:115-135

Moens T, Vincx M (2000b) Temperature, salinity and food thresholds in two brackish-water bacterivorous nematode species: assessing niches from food absorption and respiration experiments. J Exp Mar Biol Ecol 243: $137-154$

Nei M (1987) Molecular evolutionary genetics. Columbia University Press, New York

Orita M, Iwahana H, Kanazawa H, Hayashi K, Sekiya T (1989) Detection of polymorphisms of human DNA by gelelectrophoresis as single-strand conformation polymorphism. Proc Natl Acad Sci USA 86:2766-2770

Ovenden JR, Salini J, O'Connor S, Street R (2004) Pronounced genetic population structure in a potentially vagile fish species (Pristipomoides multidens, Teleostei; Perciformes; Lutjanidae) from the East Indies triangle. Mol Ecol 13:1991-1999

Palumbi SR (1994) Genetic divergence, reproductive isolation, and marine speciation. Annu Rev Ecol Syst 25: 547-572

Posada D, Crandall KA (1998) Modeltest: testing the model of DNA substitution. Bioinformatics 14:817-818
Rice WR (1989) Analyzing tables of statistical tests. Evolution 43:223-225

Rocha-Olivares A, Fleeger JW, Foltz DW (2001) Decoupling of molecular and morphological evolution in deep lineages of a meiobenthic harpacticoid copepod. Mol Biol Evol 18: 1088-1102

Schizas NV, Street GT, Coull BC, Chandler GT, Quattro JM (1999) Molecular population structure of the marine benthic copepod Microarthridion littorale along the south eastern and Gulf coasts of the USA. Mar Biol 135: 399-405

Schizas NV, Chandler GT, Coull BC, Klosterhaus SL, Quattro JM (2001) Differential survival of three mitochondrial lineages of a marine benthic copepod exposed to a pesticide mixture. Environ Sci Technol 35:535-538

Schizas NV, Coull BC, Chandler GT, Quattro JM (2002) Sympatry of distinct mitochondrial DNA lineages in a copepod inhabiting estuarine creeks in the south eastern USA. Mar Biol 140:585-594

Schneider S, Roessli D, Excoffier L (2000) Arlequin ver. 2.000: a software for population genetics data analysis. Genetics and Biometry Laboratory, University of Geneva

Slatkin M (1993) Isolation by distance in equilibrium and non-equilibrium populations. Evolution 47:264-279

Street GT, Lotufo GR, Montagna PA, Fleeger JW (1998) Reduced genetic diversity in a meiobenthic copepod exposed to a xenobiotic. J Exp Mar Biol Ecol 222:93-111

Sudhaus W (1974) Nematoden (insbesondere Rhabditiden) des Strandanwurfs und ihre Beziehungen zu Krebsen. Faun-ökol Mitt 4:365-400

Sudhaus W, Fitch D (2001) Comparative studies on the phylogeny and systematics of the Rhabditidae (Nematoda). J Nematol 33:1-70

Sudhaus W, Nimrich M (1989) Rhabditid nematodes from seaweed deposits in Canada with a description of Rhabditis (Pellioditis) littorea n. sp. Can J Zool 67:1347-1352

Sunnucks P, Wilson ACC, Beheregaray LB, Zenger K, French J, Taylor AC (2000) SSCP is not so difficult: the application and utility of single-stranded conformation polymorphism in evolutionary biology and molecular ecology. Mol Ecol 9: $1699-1710$

Swofford DL (1998) PAUP*. Phylogenetic analysis using parsimony $\left({ }^{*}\right.$ and other methods). Version 4 . Sinauer Associates, Sunderland, MA

Tajima F (1983) Evolutionary relationship of DNA sequences in finite populations. Genetics 123:585-595

Tamura K, Nei M (1993) Estimation of the number of nucleotide substitutions in the control region of mitochondrial DNA in humans and chimpanzees. Mol Biol Evol 10: 512-526

Taylor MS, Hellberg ME (2003) Genetic evidence for local retention of pelagic larvae in a Caribbean reef fish. Science 299:107-109

Todaro MA, Fleeger JW, Hu YP, Hrincevich AW, Foltz DW (1996) Are meiofaunal species cosmopolitan? Morphological and molecular analysis of Xenotrichula intermedia (Gastrotricha: Chaetonotida). Mar Biol 125:735-742

Turrell WR (1992) New hypotheses concerning the circulation of the northern North Sea and its relation to North Sea fish stock recruitment. ICES J Mar Sci 49:107-123

Vrain TC, Wakarchuk DA, Lévesque AC, Hamilton RI (1992) Intraspecific rDNA restriction fragment length polymorphism in the Xiphinema americanum group. Fundam Appl Nematol 15:563-573

Vranken G, Heip C (1983) Calculation of the intrinsic rate of natural increase, $\mathrm{r}_{\mathrm{m}}$, with Rhabditis marina Bastian 1865 (Nematoda). Nematologica 29:468-477 
Wetzel MA, Weber A, Giere O (2002) Re-colonization of anoxic/sulfidic sediments by marine nematodes after experimental removal of macroalgal cover. Mar Biol 141: 679-689

Zhu XQ, Gasser RB (1998) Single-strand conformation polymorphism (SSCP)-based mutation scanning approaches to fingerprint sequence variation in ribosomal DNA of ascaridoid nematodes. Electrophoresis 19:1366-1373

Editorial responsibility: Otto Kinne (Editor-in-Chief), Oldendorf/Luhe, Germany
Zhu XQ, Jacobs DE, Chilton NB, Sani RA, Cheng NABY, Gasser RB (1998) Molecular characterization of a Toxocara variant from cats in Kuala Lumpur, Malaysia. Parasitology $117: 155-164$

Zhu XQ, D'Amelio S, Hu M, Paggi L, Gasser RB (2001) Electrophoretic detection of population variation within Contracaecum ogmorhini (Nematoda: Ascaridoidea: Anisakidae). Electrophoresis 22:1930-1934

Submitted: December 13, 2004; Accepted: April 4, 2005

Proofs received from author(s): August 23, 2005 